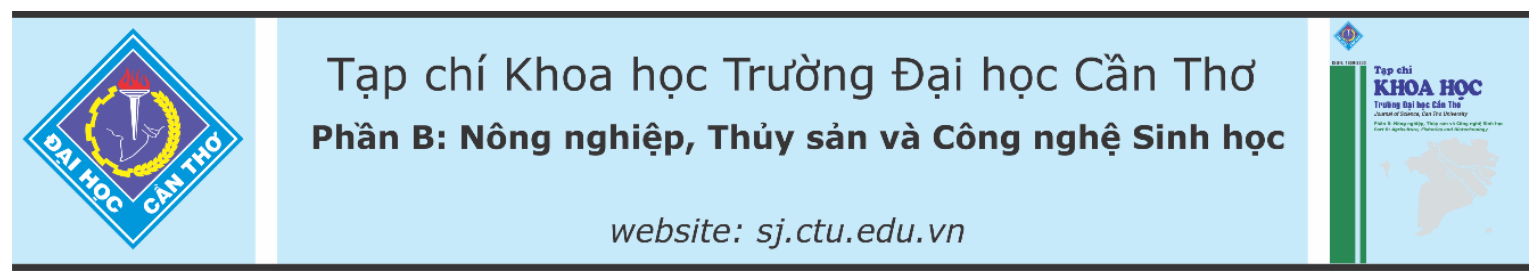

DOI:10.22144/ctu.jvn.2021.020

\title{
KHẢ NĂNG SINH TRƯỞNG VÀ TÍCH LŨY SINH KHỐI CỦA BỒN BỒN (Typha orientalis), CỎ BÀNG (Lepironia articulata) VÀ NĂN TƯợNG (Scirpus littoralis) TRỒNG TRÊN ĐẤT PHÊN
}

Võ Hoàng Việt, Võ Thị Phương Thảo, Võ Hữu Nghị, Đỗ Hữu Thành Nhân, Phạm Văn Toàn và Ngô Thụy Diễ்m Trang*

Khoa Môi truờng và Tài nguyên Thiên nhiên, Truờng Đại học Cần Tho'

"Nguoòi chịu trách nhiệm về bài viết: Ngô Thuy Diêem Trang (email: ntdtrang@ctu.edu.vn)

\section{Thông tin chung:}

Ngày nhận bài: $15 / 08 / 2020$

Ngày nhận bài sủa: 22/10/2020

Ngày duyệt đăng: 27/02/2021

\section{Title:}

Growth and biomass allocation in cattail (Typha orientalis), grey sedge (Lepironia articulata) and bulrush (Scirpus littoralis) on acid sulfate soils

\section{Tù khóa:}

Bồn bồn, cỏ bàng, đất phèn, năn tượng, sinh khối, vôi

\section{Keywords:}

Acid sulfate soils, biomass, Lepironia articulata, lime, Scirpus littoralis, Typha orientalis

\begin{abstract}
The study was conducted to evaluate plant growth and biomass of three aquatic plants including cattail (Typha orientalis C. Presl), grey sedge (Lepironia articulata Retz. Domin.), and bulrush (Scirpus littoralis Schrad.), which were grown on acid sulfate soils in the Mekong Delta. Before planting, soil pH improvement in acid sulfate soil using $\mathrm{CaCO}_{3}$ was studied with two-ton $\mathrm{CaCO}_{3} / \mathrm{ha}$ and without $\mathrm{CaCO}_{3}$ (considered as control treatment). The soil was continued to grow the three studied plants, which were conducted in a completely randomized design with 3 replications. The results showed that applying and soaking acid sulfate soil with $\mathrm{CaCO}_{3}$ for 42 days, the $\mathrm{pH}$ soil was improved 4.02 and higher than that of the initial soil ( $\mathrm{pH}=3.02)$. After 90 days of planting, the growth, fresh and dry biomass accumulation in the shoots and roots and leaves total chlorophyll content (SPAD) of T. orientalis and S. littoralis were higher in the acid sulfate soils applied $\mathrm{CaCO}_{3}$.
\end{abstract}

\section{TÓM TẮT}

Nghiên cưu được thực hiện nhằm đánh giá khả năng sinh truởng và tích lüy sinh khối ở ba loài thực vật thủy sinh gồm bồn bồn (Typha orientalis C. Presl), cỏ bàng (Lepironia articulata Retz. Domin.) và năn tuợng (Scirpus littoralis Schrab.) trồng trên đất phèn ở Đồng bằng sông Cửu Long. Truớc khi trồng cây, thí nghiệm đánh giá khả năng cải thiện pH đất bằng $\mathrm{CaCO}_{3}$ được thực hiện trên 2 nghiệm thức bón 2 tấn $\mathrm{CaCO}_{3} / h a$ và không bón $\mathrm{CaCO}_{3}$ (được xem là nghiệm thức đối chứng). Đất này được sủ dụng để trồng cây cho thí nghiệm tiếp theo với ba loài cây, bố trí theo thể thức hoàn toàn ngẫu nhiên với ba lân lặp lại. Sau 42 ngày ngâm đất, giá trị pH trong đất đạt 4,02 ở nghiệm thiúc có $\mathrm{CaCO}_{3}$ và cao hơn so với đất ban đầu (pH=3,02). Sau 90 ngày trồng cây, khả năng sinh trưởng và tiềm năng tích lũy sinh khối tuơi và khô của phần thân và rễ cây và chi số diệp luc tố (SPAD) của bồn bồn và năn tuợng tốt hơn khi cây trồng trên đất phèn có bón $\mathrm{CaCO}_{3}$. 


\section{GIỚI THIÊU}

Đất phèn chiếm $40 \%$ diện tích đất ở vùng đồng bằng sông Cửu Long (ĐBSCL), tương ứng khoảng 1,6 triệu ha (Xuan and Matsui, 1998). Đất phèn có $\mathrm{pH}$ thấp, do đó hàm lượng nhôm và sắt trong đất ở dạng hòa tan cao, ức chế tăng trưởng thực vật, bao gồm cả sự tăng trưởng của rễ và chức năng của rễ (Kochian et al., 2005). Phèn được sinh ra có thể do nguyên nhân oxy hóa phèn tiềm tàng $(\mathrm{FeS})$ tại chỗ tạo thành axit $\mathrm{H}_{2} \mathrm{SO}_{4}$ chứa nhiều độc chất $\mathrm{Al}^{3+}, \mathrm{Fe}^{2+}$, $\mathrm{SO}_{4}{ }^{2-}$. Đối với cây trồng, độ chua của đất là một phức hợp của nhiều yếu tố liên quan đến thiếu hụt chất dinh dưỡng và độc tính, hoạt động vi sinh vật có lợi thấp và giảm sự phát triển của rễ cây làm hạn chế hấp thu chất dinh dưỡng và nước (Fageria and Baligar, 2003). Những thay đổi trong hóa học đất có mối tương quan tích cực với phân bố và sự phát triển của rễ. Điều này đã tạo ra sự ức chế tăng trưởng do tính axit của đất bởi một số loài thực vật nhạy cảm với $\mathrm{pH}$ thấp.

Theo Lê Văn Dũng và $c t v$. (2018), sử dụng $\mathrm{CaCO}_{3}$ và kết hợp bón phân hữu cơ trên đất phèn nhiễm mặn canh tác lúa giúp gia tăng độ $\mathrm{pH}$ của đất, giảm độc chất nhôm, giúp cải thiện năng suất lúa. Đất có bón vôi $\mathrm{CaCO}_{3}$, do có các muối carbonate và biocarbonate của ion $\mathrm{Ca}^{2+}$ chiếm ưu thế đã làm $\mathrm{pH}$ đất tăng (Sardinha et al., 2003). Bên cạnh đó vôi làm tăng $\mathrm{pH}$ đất để kết tủa với $\mathrm{Al}^{3+}$ như nhôm hydroxit, do đó làm giảm độc tính của chúng (Shamshuddin et al., 2010). Opala (2017) cũng ghi nhận bón 2 tấn $\mathrm{CaCO}_{3}$ kết hợp với $30 \mathrm{~kg}$ P/ha năng suất cây bắp đạt cao nhất.

Bồn bồn (Typha orientalis), cỏ bàng (Lepironia articulata) và năn tượng (Scirpus littoralis) được biết đến là các loài thực vật ngập nước phổ biến, có khả năng sinh trưởng trong đất hiếm khí và ngập nước. Theo Valipour and Ahn (2016), bồn bồn có thể chịu được điều kiện axit vừa phải và độ $\mathrm{pH}$ khá rộng là 4,0-10,0; trong khi năn tượng là loài thực vật có mạch và chiếm ưu thế nơi có điều kiện axit thấp hơn là 4,0-5,0 (Fältmarsch et al., 2008) và cỏ bàng cũng có khả năng sống trên đất phèn vừa phải đến phèn nặng và $\mathrm{pH}$ rất thấp trong khoảng 2,8-3,3 (Kawahigashi et al., 2008). Ngoài ra, ba loài cỏ này có giá trị sinh khối cao, và sinh khối dùng để dệt chiếu và sản xuất các loại sản phẩm thủ công khác nhau từ cỏ bàng (Huu, 2017) hay thân cây năn tượng được sử dụng để dệt và tạo ra các sản phẩm thủ công, làm nhiên liệu và thay thế cho dây (Macia and Balslev, 2000), cung cấp thức ăn thô xanh dinh dưỡng cao và là nguồn thức ăn cho gia súc (Beetle, 1941; Macia and Balslev, 2000). Bên cạnh đó, bồn bồn được trồng trên ruộng lúa và trong ao nuôi tôm ở ĐBSCL để làm nguồn thực phẩm cho con người và gia súc (Trang et al., 2002; Trang et al., 2018). Tuy nhiên, khả năng sinh trưởng và tích lũy sinh khối của bồn bồn, cỏ bàng và năn tượng trồng trên đất phèn vẫn có ít thông tin, cụ thể trên đất phèn trũng nước bỏ hoang không canh tác ở tỉnh Vĩnh Long. Do đó, việc nghiên cứu và sử dụng đất phèn để canh tác các loài cỏ tiềm năng sinh khối là giải pháp cần thiết để khai thác và sử dụng hợp lí tài nguyên đất, đặc biệt là đất phèn hạn chế canh tác nông nghiệp.

\section{PHƯƠNG PHÁP NGHIÊN CÚU}

\subsection{Chuẩn bị thí nghiệm}

\subsubsection{Chuẩn bị đất}

Đất sử dụng cho thí nghiệm được lấy tầng mặt $(0-20 \mathrm{~cm})$ trên đất phèn ngập nước không canh tác nông nghiệp tại xã Vĩnh Xuân, huyện Trà Ôn, tỉnh Vĩnh Long $\left(9^{\circ} 57^{\prime} 16.0^{\prime \prime} \mathrm{N}\right.$ và $\left.106^{\circ} 00^{\prime} 29.0^{\prime \prime} \mathrm{E}\right)$. Khối đất lấy có đường kính $\mathrm{x}$ chiều cao $(\mathrm{cm})$ tương ứng là $21 \times 28 \mathrm{~cm}$ và có khối lượng trung bình $10,21 \pm 0,20 \mathrm{~kg}$, khối đất được cố định để giữ nguyên khối bằng ống nhựa PVC. Đất trước khi thí nghiệm được phân tích xác định một số chỉ tiêu lý hóa đất đầu vào (Bảng 1). Theo thang phân loại đất của Soil Survey Division Staff (1993), dất sử dụng cho thí nghiệm là đất phèn có tính axit rất nặng $(\mathrm{pH}<3,5)$, do đó, cần kết hợp bón $\mathrm{CaCO}_{3}$ để cải thiện $\mathrm{pH}$ trong đất trước khi trồng cây.

\section{Bảng 1. Một số đặc tính lý hóa đất ban đầu sử dụng trong thí nghiệm}

\begin{tabular}{llr}
\hline Chỉ tiêu & Đơn vị & Giá trị \\
\hline Độ ẩm & $\%$ & $31,05 \pm 0,14$ \\
EC $_{\mathrm{H} 2 \mathrm{O}}(1: 5)$ & $\mathrm{mS} / \mathrm{cm}$ & $0,50 \pm 0,28$ \\
$\mathrm{pH}$ & $3,02 \pm 0,18$ \\
Tỷ trọng & - & $2,14 \pm 0,05$ \\
Chất hữu cơ & \% $/ \mathrm{cm}^{3}$ & $1,12 \pm 0,03$ \\
Thành phần cơ & \%cát:\%sét: & 23,91:32,83:43,36 \\
giới đất & \%thịt & \\
\hline
\end{tabular}

Ghi chú: số liệu trình bày dạng trung bình \pm độ lệch chuẩn $(S D)(n=2)$

\subsubsection{Chuẩn bi cây giống}

Cây giống bồn bồn và năn tượng được thu tại các ao canh tác mô hình tôm-cỏ ở Phong Thạnh $\mathrm{A}$, Giá Rai, Bạc Liêu $\left(9^{\circ} 15^{\prime} 34.1^{\prime \prime N}\right.$ và $\left.105^{\circ} 24^{\prime} 54.2^{\prime \prime E}\right)$, riêng cỏ bàng được thu ở Phú Mỹ, Giang Thành, tỉnh Kiên Giang (10²6'22.4"N và 104³6'11.6"E). Cây được chọn làm thí nghiệm là những cây con, khá đồng đều về độ tuổi, kích cỡ và sinh khối, chiều cao các cây chọn để bố trí thí nghiệm. 


\subsection{Bố trí thí nghiệm}

2.2.1. Thí nghiệm 1: Khả năng cải thiện $\mathrm{pH}$ của $\mathrm{CaCO}_{3}$ trên đất phèn

Giá trị $\mathrm{pH}$ của đất thấp $(\mathrm{pH}=3,02)$, do đó, thí nghiệm 1 được thực hiện nhằm mục tiêu cải thiện giá trị $\mathrm{pH}$ trong đất phèn bằng $\mathrm{CaCO}_{3}$ (độ tinh khiết $\geq 99,5 \%$ ) trước khi trồng cây. Thí nghiệm bố trí hoàn toàn ngẫu nhiên với hai nghiệm thức không bón $\mathrm{CaCO}_{3}$ và có bón $\mathrm{CaCO}_{3}$. Lượng vôi sử dụng là 2 tấn/ha theo khuyến cáo của Opala (2017) trên đất phèn, tương đương $10,18 \pm 0,19 \mathrm{~g} / \mathrm{chậu}$. Thí nghiệm thực hiện trong chậu có đường kính lớn $\mathrm{x}$ đường kính nhỏ $\mathrm{x}$ chiều cao lần lượt là $28 \times 19 \times 21 \mathrm{~cm}$. Thí nghiệm chia thành 3 lần ngâm đất (các mốc thời gian sử dụng ngâm đất được dựa theo kết quả ghi nhận của (Trịnh Thị Thu Trang và Nguyễn Mỹ Hoa, 2007) ghi nhận sau 70 ngày ngâm ủ đất có sự hiện diện của vôi đã cải thiện $\mathrm{pH}$ trong đất phèn Hòa An và Tiền Giang, tăng từ $<4$ lên $>5$ :

- Ngâm lần 1: Ngâm đất với 2 L nước máy (đã bay hơi chlorine trong 2-3 ngày) trong vòng 28 ngày, sau đó bơm nước ngâm ra ngoài và thu mẫu đất lần 1 .

- Ngâm lần 2: Lượng $\mathrm{CaCO}_{3}$ được hòa chung với $2 \mathrm{~L}$ nước ngâm và ngâm tiếp trong vòng 14 ngày, sau 14 ngày ngâm, tiến hành bơm nước ngâm ra ngoài và thu mẫu đất lần 2 (sau 42 ngày ngâm).

- Ngâm lần 3: ngâm đất trong vòng 28 ngày tiếp theo bằng nước máy và đến ngày thứ 70 kết thúc thí nghiệm, bơm nước ra ngoài và tiến hành thu mẫu đất lần 3 .

2.2.2. Thí nghiệm 2: Khả năng sinh trường của bồn bồn, cỏ bàng và năn tượng trồng trên đất phèn đã cải thiện $\mathrm{pH}$

Sau khi kết thúc 70 ngày ngâm đất, tiến hành trồng cây vào chậu (diện tích bề mặt là $0,23 \mathrm{~m}^{2}$ và chiều cao chậu là $21 \mathrm{~cm}$ ). Mật độ cây trồng là 3 bụi/chậu (Trang et al., 2018) (Hình 2). Thí nghiệm 2 được bố trí theo thể thức hoàn toàn ngẫu nhiên, với 3 lần lặp lại cho mỗi nghiệm thức, bao gồm nhân tố $(\mathrm{A})$ : 3 loài cây bao gồm bồn bồn, cỏ bàng và năn tượng và nhân tố $(\mathrm{B})$ : gồm 2 mức độ bón (không bón và bón phân $\mathrm{CaCO}_{3}$ ). Mức nước trong chậu được thường xuyên kiểm tra và duy trì ở mức $5 \mathrm{~cm}$ trên bề mặt đất.

\subsection{Phương pháp thu mẫu cây và mẫu đất}

- Thu mẫu đất: đất sau các lần ngâm được thu bằng khoan đất để xác định tính chất đất sau mỗi lần ngâm. Sau khi thu mẫu, một phần mẫu đất được xác định độ ẩm bằng cách sấy ở nhiệt độ $105^{\circ} \mathrm{C}$ đến khi trọng lượng không đổi, phần còn lại phơi khô ở nhiệt độ phòng, sau đó được nghiền qua rây $0,5 \mathrm{~mm}$ để sử dụng phân tích. Ly trích đất với tỉ lệ tương ứng là 1:5 (đất:nước), ly tâm 15 phút với tốc độ 3.000 vòng/phút, dung dịch trích từ đất được xác định $\mathrm{pH}$ (bằng máy đo Hanna 8424 , Rumani) và $\mathrm{EC}$ (bằng máy đo HI99301, Rumani).

- Thu mẫu cây: sau 90 ngày trồng cây, tiến hành thu cây xác định chiều cao cây, chiều dài rễ, sinh khối tươi thân và rễ, sinh khối khô thân và rễ cây (được sấy ở nhiệt độ $60-70^{\circ} \mathrm{C}$ cho đến khi khối lượng không đổi). Dựa vào kết quả sinh khối tính tốc độ tăng trưởng sinh khối theo thời gian (g/ngày). Bên cạnh đó, tốc độ tăng trưởng tương đối RGR (mg/g/ngày) cũng được tính toán theo công thức của Fisher (1921).

$$
\operatorname{RGR}\left(\frac{\frac{\mathrm{mg}}{\mathrm{g}}}{\mathrm{ngày}}\right)=\frac{(\operatorname{lnw} 2-\ln W 1)}{\mathrm{t} 1-\mathrm{t} 2}
$$

Trong đó, W1, W2 (mg) là khối lượng cây tại thời điểm bắt đầu bố trí thí nghiệm $\mathrm{t} 1$ và thời gian thu hoạch $\mathrm{t} 2$ (ngày).

Chỉ số diệp lục trong lá được xác định bằng cách sử dụng máy đo diệp lục cầm tay SPAD-502 (Minolta, Osaka, Nhật Bản), đây là phương pháp xác định chlorophyll nhanh chóng và không phá hủy lá. Chỉ số SPAD được đo ở vị trí $2 / 3$ của lá tính từ cuống lá đến chóp lá để có được chỉ số diệp lục tố tối ưu (Yuan et al., 2016). Lá được đo chỉ số SPAD trước khi tiến hành đo các chỉ tiêu sinh trưởng như chiều cao cây, đếm số lá. Tiến hành thu cây bằng cách loại bỏ đất khỏi hệ rễ, rửa sạch rễ, đo chiều dài rễ. Cây được cắt phần thân và phần rễ để cân sinh khối tươi thân, rễ và sấy để xác định sinh khối khô thân, rễ.

\subsection{Phương pháp xử lý số liệu}

Số liệu các lần lặp lại của từng chỉ tiêu được tổng hợp, tính toán bằng phần mềm Microsoft Excel 2013. Sử dụng phần mềm thống kê Statgraphic Centurion XX (StatPoint, Inc., USA) để phân tích phương sai hai nhân tố (two-way ANOVA) và một nhân tố (one-way ANOVA). So sánh trung bình các nghiệm thức dựa vào kiểm định Tukey ở mức $5 \%$. So sánh hai trung bình dựa vào kiểm định $\mathrm{T}$-test ở mức 5\%. Sử dụng phần mềm Sigmaplot 14.0 (San Jose, California, USA) để vẽ biểu đồ.

\section{KẾT QUẢ VÀ THẢO LUẬN \\ 3.1. Khả năng cải thiện $\mathrm{pH}$ trong đất phèn của $\mathrm{CaCO}_{3}$}

Giá trị $\mathrm{pH}$ trong đất sau 28 ngày ngâm nước có kết quả như nhau giữa 2 nghiệm thức $(\mathrm{p}>0,05$; Hình 
1A), nhưng sau khi bón $\mathrm{CaCO}_{3} \mathrm{pH}$ trong đất có sự khác biệt giữa 2 nghiệm thức, cụ thể $\mathrm{pH}$ đất ở nghiệm thức có bón $\mathrm{CaCO}_{3}$ cao hơn nghiệm thức không bón $\mathrm{CaCO}_{3}$ (p>0,05; Hình 1A). Sử dụng vôi là cách quản lý hiệu quả nhất để giảm độ chua của đất (Fageria and Baligar, 2008) và tạo điều kiện cho sự phát triển của cây trồng trong đất phèn bằng cách tăng $\mathrm{pH}$ đất (Cho et al., 2002). Giá trị pH ở nghiệm thức có bón $\mathrm{CaCO}_{3}$ cao hơn ở nghiệm thức không bón $\mathrm{CaCO}_{3}$, cụ thể ở mốc thời gian sau khi bón $\mathrm{CaCO}_{3}$ (ngày thứ 42 và $70 ; p<0,05 ;$ Hình $1 \mathrm{~A}$ ), điều này cho thấy $\mathrm{CaCO}_{3}$ góp phần hiệu quả trong cải thiện $\mathrm{pH}$ đất. Giá trị pH đất sau khi bón bổ sung $\mathrm{CaCO}_{3}$ nằm trong ngưỡng thích nghi cho sự sinh trưởng và phát triển của cả 3 loài cỏ nghiên cứu (Fältmarsch et al., 2008; Kawahigashi et al., 2008; Valipour and Ahn, 2016). Nhìn chung, sau 70 ngày ngâm đất, $\mathrm{pH}$ đất tăng theo thời gian $(\mathrm{p}<0,05$; Hình 1A), có giá trị trung bình là 3,8-4,0 cao hơn so với $\mathrm{pH}$ trong đất ban đầu $(\mathrm{pH}=3,02)$. Sự cải thiện $\mathrm{pH}$ trong đất phèn là rất cần thiết, vì trong điều kiện $\mathrm{pH}<3,5$ dẫn đến sự hòa tan của các yếu tố có hại như $\mathrm{Al}, \mathrm{Fe}, \mathrm{Mn}$ (Ueno, 2004) sẽ gây bất lợi cho sự phát triển của cây trồng.
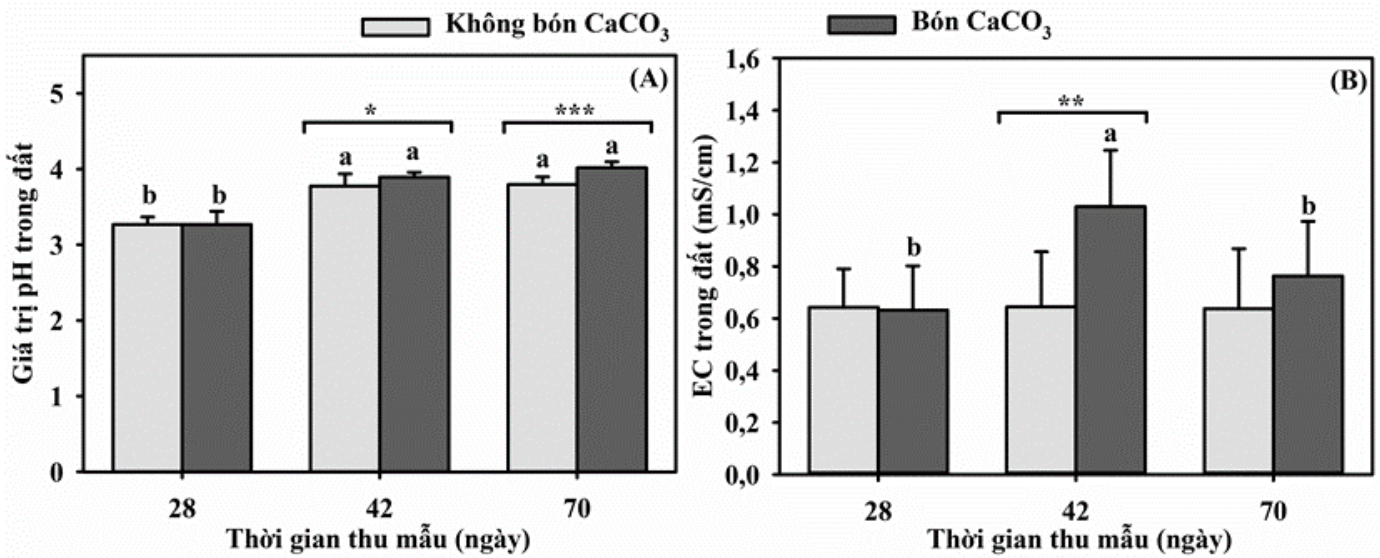

Hình 1. Giá trị pH (A) và EC (D) trong đất theo thời gian thu mẫu

Ghi chú: a,b: giá trị trung bình có ki tụ a,b khác nhau thì khác biệt có ý nghĩa thống kê giữa các mốc thời gian trong cùng một nghiệm thức dựa vào kiểm định Tukey $(p<0,05)$. (*) chỉ ra sụ khác biệt giữa hai nghiệm thức trong cùng một mốc thời gian dựa vào kiểm định T-test $(* p<0,05 ; * * p<0,01 ; * * * p<0,001)$.

Độ dẫn điện (EC) trong dung dịch đất tăng cao nhất sau 42 ngày ngâm ở nghiệm thức có bón $\mathrm{CaCO}_{3}$ $(\mathrm{p}<0,05 ;$ Hình $1 \mathrm{~B})$. Điều này có thể do đất sử dụng là đất phèn rất nặng $(\mathrm{pH}<3,5)$, do đó, vôi được hòa tan tạo $\mathrm{ra} \mathrm{Ca}^{2+}$ và $\mathrm{OH}^{-}$, sản phẩm $\mathrm{Ca}^{2+}$ tham gia trao đổi với $\mathrm{Al}^{3+}$ và $\mathrm{H}^{+}$trong keo đất, đồng thời lượng $\mathrm{OH}^{-}$dư sẽ phản ứng với $\mathrm{Al}^{3+}$ thành $\mathrm{Al}(\mathrm{OH})_{3}$ trên bề mặt đất (Uchida and Hue, 2000), và làm tăng tính tan một số ion như $\mathrm{Mn}^{2+}$ và $\mathrm{Fe}^{2+}$, dẫn đến làm tăng giá trị $\mathrm{EC}$ trong dung dịch đất. Đồng thời sau lần ngâm thứ 3 , các cation trên bề mặt của khối đất được rửa trôi, do đó, giá trị $\mathrm{EC}$ trong đất giảm tương đương $\mathrm{EC}$ trong đất sau 28 ngày.

\subsection{Chiều cao cây và chiều dài rễ}

Kết quả phân tích phương sai hai nhân tố cho thấy tất cả các chỉ tiêu sinh trưởng và sinh khối đều có sự tương tác giữa hai nhân tố loài cây và bón phân $(\mathrm{p}<0,05$; Bảng 2$)$, ngoại trừ chỉ tiêu chiều cao cây và tốc độ tăng trưởng chiều cao cây $(\mathrm{p}>0,05)$, nhưng hai nhân tố này ảnh hưởng đến hai chỉ tiêu trên $(\mathrm{p}<0,05)$. 
Bảng 2. Kết quả phân tích phương sai hai nhân tố (giá trị F) các chỉ tiêu sinh trưởng của bồn bồn, cỏ bàng và năn tượng trồng trong đất phèn

\begin{tabular}{|c|c|c|c|c|}
\hline \multirow{2}{*}{ Chỉ tiêu } & \multicolumn{2}{|c|}{ Nhân tố chính } & \multirow{2}{*}{$\begin{array}{l}\text { Tương tác } \\
\left(\begin{array}{l}A \\
\times\end{array}\right)\end{array}$} & \multirow{2}{*}{ Sai số } \\
\hline & Loài cây (A) & Bón $\mathrm{CaCO}_{3}(\mathrm{~B})$ & & \\
\hline$\overline{\text { Chiều cao cây }}$ & $41,58^{* * *}$ & $47,19^{* * *}$ & $3,44^{\mathrm{ns}}$ & 21,5 \\
\hline Tốc độ tăng chiều cao cây & $58,49^{* * *}$ & $46,25^{* * *}$ & $3,39^{\text {ns }}$ & 0,00 \\
\hline Chiều dài rễ & $103,18^{* * *}$ & $128,03^{* * *}$ & $14,07^{* * *}$ & 2,86 \\
\hline Tốc độ tăng chiều cao cây & $139,56^{* * *}$ & $122,73^{* * *}$ & $12,59^{* * *}$ & 0,00 \\
\hline Tỉ lệ rễ/thân & $181,73^{* * *}$ & $31,50^{* * *}$ & $9,05^{* *}$ & 0,00 \\
\hline Số lá & $85,04^{* * *}$ & $22,62^{* * *}$ & $5,05^{*}$ & 4,79 \\
\hline Sinh khối tươi thân & $68,77^{* * *}$ & $85,30^{* * *}$ & $23,66^{* * *}$ & 3,54 \\
\hline Tốc độ tăng sinh khối tươi & $63,31^{* * *}$ & $78,28^{* * *}$ & $19,65^{* * *}$ & 0,00 \\
\hline Sinh khối khô thân & $16,09^{* * *}$ & $70,14^{* * *}$ & $11,73^{* *}$ & 0,32 \\
\hline Tốc độ tăng sinh khối khô thân & $16,00^{* * *}$ & $69,14^{* * *}$ & $16,00^{* * *}$ & 0,00 \\
\hline Sinh khối tươi rễ & $1646,17^{* * *}$ & $639,00^{* *}$ & $330,86^{* * *}$ & 3,09 \\
\hline Tốc độ tăng sinh khối tươi rễ & $1116,44^{* * *}$ & $630,00^{* * *}$ & $326,61^{* * *}$ & 0,00 \\
\hline Sinh khối khô rễ & $217,46^{* * *}$ & $86,58^{* * *}$ & $17,84^{* * *}$ & 1,02 \\
\hline Tốc độ tăng sinh khối khô rễ & $272,39^{* * *}$ & $107,56^{* * *}$ & $22,72^{* * *}$ & 0,00 \\
\hline RGR thân & $99,97^{* * *}$ & $78,92^{* * *}$ & $13,88^{* * *}$ & 0,44 \\
\hline RGR rê̂ & $421,80^{* * *}$ & $52,08^{* * *}$ & $3,64^{\mathrm{ns}}$ & 1,71 \\
\hline SPAD & $604,54^{* * *}$ & $69,75^{* * *}$ & $7,76^{* *}$ & 0,30 \\
\hline
\end{tabular}

Ghi chú: ${ }^{*} p<0,05 ;{ }^{*} p<0,01$; **p<0,001: Khác biệt có ý nghĩa ở múc 5\%, $1 \%$ và 0,1\%; ns: khác biệt không có ý nghĩa thống kê $(p>0,05)$.

Chiều cao cây $(99,3-130,5 \mathrm{~cm})$ và tốc độ tăng trưởng chiều cao cây $(0,27-0,63 \mathrm{~cm} /$ ngày $)$ của cả 3 loài cỏ ở nghiệm thức bón $\mathrm{CaCO}_{3}$ cao hơn ở nghiệm thức không bón $\mathrm{CaCO}_{3}(\mathrm{p}<0,05$; Hình $3 \mathrm{~A}$ và $3 \mathrm{~B})$. Việc sử dụng $\mathrm{CaCO}_{3}$ cải tạo đất đồng thời giúp cây sinh trưởng tốt hơn và cải thiện chiều cao cây $17,1 \%$ ở Bồn bồn (Hình 2A), 12,8\% ở cỏ Bàng (Hình 2B) và $8,4 \%$ ở Năn tượng (Hình 2C). Ghi nhận tương tự bởi Doss et al. (1979), sử dụng vôi đã làm tăng chiều cao cây, và Moges et al. (2017) cũng ghi nhận ở nghiệm thức sử dụng vôi cho thấy chiều cao cây cải thiện $16,02 \%$ so với đối chứng, đồng thời sự tăng chiều cao cây tỷ lệ thuận với lượng vôi sử dụng trên đất chua.
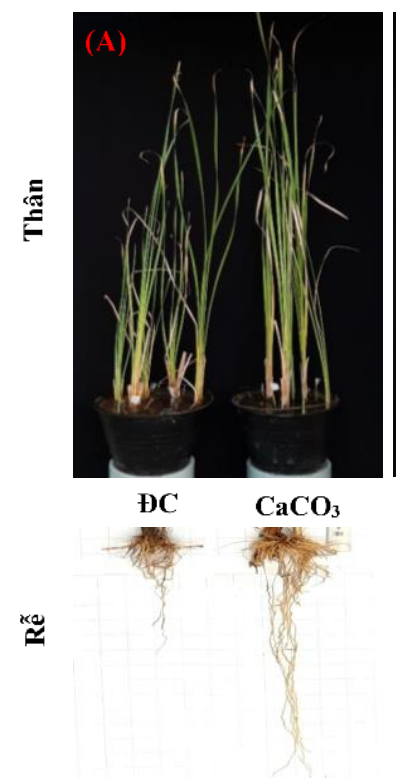
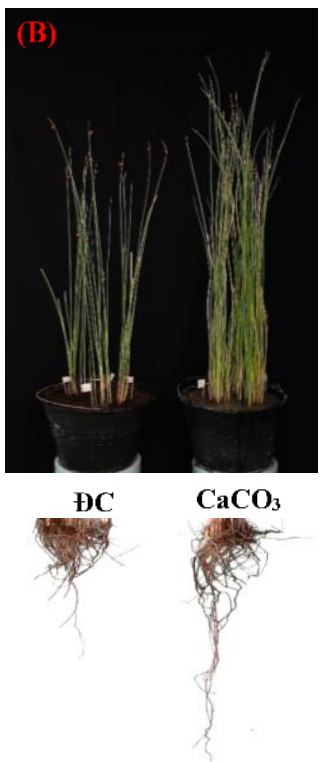
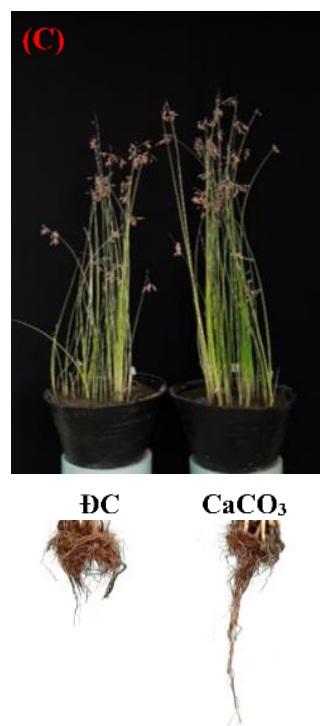

Hình 2. Hình thái thân và rễ của cây bồn bồn $(\mathrm{A})$, cỏ bàng $(\mathrm{B})$ và năn tượng $(\mathrm{C})$ ở nghiệm thức đối chứng (ĐC, không bón $\left.\mathrm{CaCO}_{3}\right)$ và nghiệm thức có bón $\mathrm{CaCO}_{3}$ 
Khác với chiều cao cây, có sự tương tác giữa hai nhân tố loài cây và bón phân về chiều dài rễ và tốc độ tăng trưởng chiều dài rễ ( $\mathrm{p}<0,05$; Bảng 2$)$. Chiều dài rễ cây đạt trung bình $28,1-43,4 \mathrm{~cm}$ và tăng 12,9 $34,4 \%$ ở nghiệm thức có bón $\mathrm{CaCO}_{3}$ (Hình 2 và Hình $3 \mathrm{C}$ ). Trong đó, chiều dài rễ tốt nhất được ghi nhận ở cỏ Bàng $43,4 \mathrm{~cm}$ và tốc độ tăng trưởng chiều dài rễ đạt $0,33 \mathrm{~cm} /$ ngày, cao hơn so với nghiệm thức đối chứng $(0,16 \mathrm{~cm} / \mathrm{ngày})$. Theo Caires et al. (2006), sự phát triển của rễ cây được cải thiện bởi sự gia tăng giá trị $\mathrm{pH}$ đất, độ bão hòa $\mathrm{Ca}^{2+}$ có thể trao đổi trong đất phèn do bón vôi. Rễ cây Bồn bồn có màu vàng nhạt, từng sợi rễ riêng biệt phát triển tốt nhưng không phân nhánh tốt (Hình $2 \mathrm{~A})$. Ngọn rễ và rễ bên của Năn tượng và cỏ Bàng có màu sẫm và chuyển sang màu nâu ở nghiệm thức đối chứng, có thể liên quan đến độc tính của nhôm trong đất phèn (Hình $2 \mathrm{~B}$ và $2 \mathrm{C})$ (Roy et al., 1988). Đồng thời mật độ rễ và chiều dài rễ có sự tương quan thuận với $\mathrm{CaCO}_{3}$ Caires et al. (2006). Quá trình ngâm đất với vôi đã góp phần cung cấp một lượng $\mathrm{OH}^{-}$từ phản ứng thủy phân và kết tủa với nhôm trao đổi tạo thành $\mathrm{Al}(\mathrm{OH})_{3}$ và phản ứng với $\mathrm{SO}_{4}{ }^{2-}$ tạo thành các cặp ion như $\mathrm{Al}$ -
$\mathrm{SO}_{4}$, giảm độc tính của nhôm trong đất (Sumner $e t$ $a l ., 1990)$ và tạo điều kiện thuận lợi cho sự phát triển của rễ cây.

\subsection{Sinh khối tươi của thân và rễ}

Có sự tương tác giữa hai nhân tố loài cây và phân bón đến sinh khối tươi của thân và tốc độ tăng trưởng sinh khối tươi phần thân ( $\mathrm{p}<0,05$; Bảng 2$)$. Sinh khối tươi thân của cây bồn bồn và năn tượng đạt 41,9-48,4 g/bụi ở nghiệm thức bón $\mathrm{CaCO}_{3}$ và cao hơn so với cây ở nghiệm thức không bón $\mathrm{CaCO}_{3}$ (31,7-36,8 g/bụi). Kết quả cho thấy sự tăng trưởng sinh khối tươi của bồn bồn là cao nhất $0,28 \mathrm{~g} /$ ngày và tăng $34,5 \%$ sinh khối tươi thân so với nghiệm thức không bón vôi. Cây năn tượng trồng trên đất phèn có bón $\mathrm{CaCO}_{3}$ trong thí nghiệm hiện tại có khả năng tích lũy sinh khối tươi của thân tương đương với ghi nhận của Han et al. (2019), trồng năn tượng trong điều kiện dinh dưỡng Hoagland đầy đủ nguyên tố đa và vi lượng cho cây trồng. Qua đó cho thấy điều kiện đất phèn được cải thiện $\mathrm{pH}$ mức 4,02 ; là khoảng $\mathrm{pH}$ thích hợp cho năn tượng sinh trưởng và đạt sinh khối tốt (Fältmarsch et al., 2008).

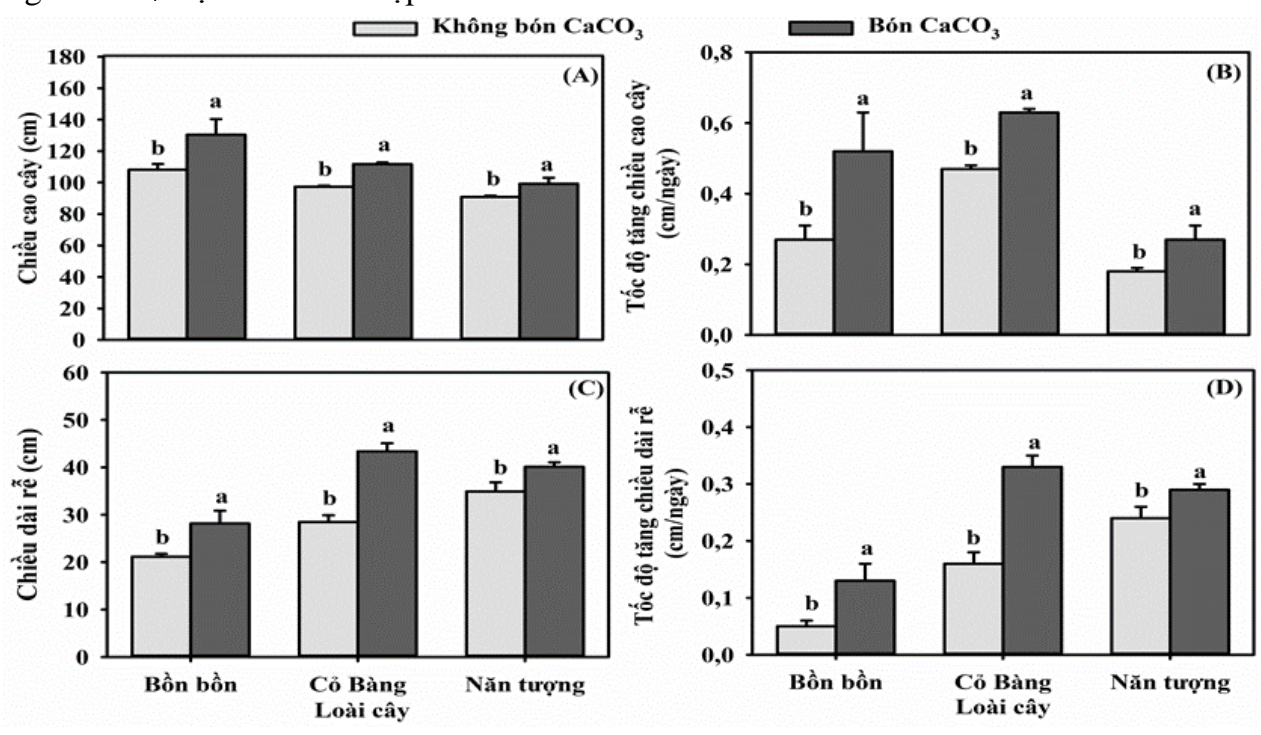

Hình 3. Chiều cao cây $(\mathrm{A})$, tốc độ tăng trưởng chiều cao cây $(\mathrm{B})$, chiều dài rễ $(\mathrm{C})$ và tốc độ tăng trưởng chiều dài rễ (D) của bồn bồn, cỏ bàng và năn tượng ở nghiệm thức không bón $\mathrm{CaCO}_{3}$ và có bón $\mathrm{CaCO}_{3}$

Ghi chú: a,b: giá trị trung bình có kí tụ a,b khác nhau thì khác biệt có ý nghĩa thống kê giũa hai nghiệm thức bón phân trong cùng một loài cây dựa vào kiểm định T-test $(p<0,05)$.

Tương tự sinh khối tươi thân, sinh khối tươi của rễ của cây trồng trên đất phèn có bón $\mathrm{CaCO}_{3}$ cũng cao hơn khoảng $15,7-51,5 \%$ so với cây trồng ở nghiệm thức không bón $\mathrm{CaCO}_{3}(\mathrm{p}<0,05$; Hình $4 \mathrm{C}$ và 4D). Sinh khối tươi phần rễ của cây bồn bồn đạt 98,8 $\mathrm{g} /$ bụi và tốc độ tăng sinh khối tươi rễ $0,91 \mathrm{~g} /$ ngày là cao nhất và thấp nhất ở loài cỏ Bàng $(17,03 \mathrm{~g} /$ bụi và
$0,11 \mathrm{~g} /$ ngày). Tóm lại, sự tăng trưởng rễ cây ở nghiệm thức không bón $\mathrm{CaCO}_{3}$ thấp hơn, có thể do độc tố nhôm, được coi là yếu tố hạn chế tăng trưởng quan trọng nhất đối với thực vật, phản ứng chính của nhôm diễn ra ở vùng rễ và điều này làm cho rễ cây bị tổn thương và kém phát triển hơn (Carver and Ownby, 1995). Do đó, sử dụng $\mathrm{CaCO}_{3}$ góp phần cải 
thiện đặc tính $\mathrm{pH}$ đất và giúp rễ cây phát triển tốt hơn trong điều kiện đất phèn. Caires et al. (2006)
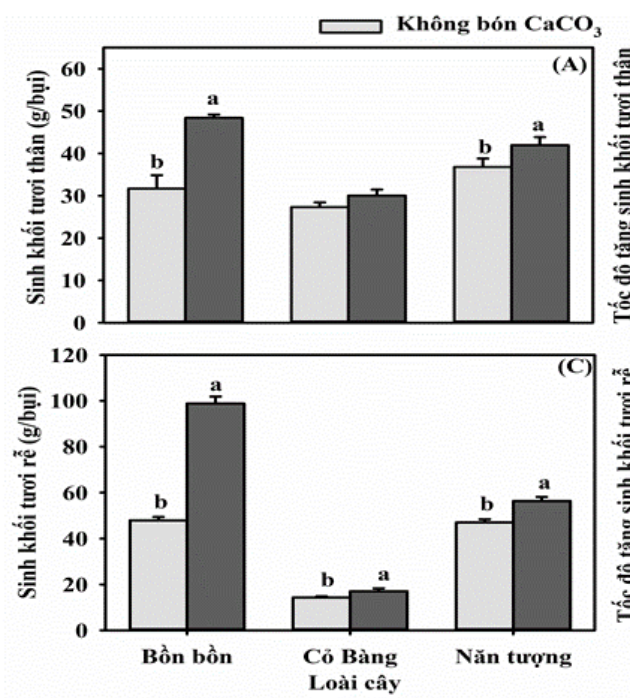

ghi nhận hiệu quả của việc bón vôi trên bề mặt đất góp phần $66 \%$ trong sự tăng trưởng ở rễ lúa mì.

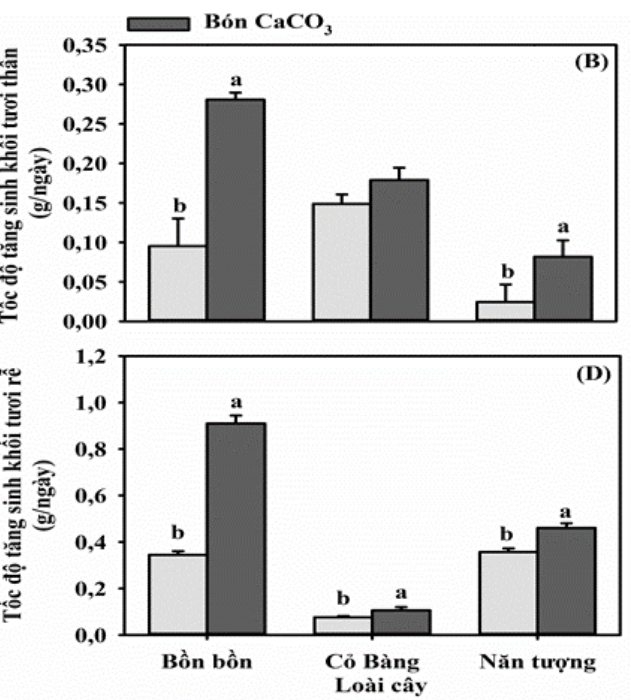

Hình 4. Sinh khối tươi thân (A), tốc độ tăng sinh khối tươi thân (B), sinh khối tươi rễ (C) và tốc độ tăng sinh khối tươi rễ $(\mathrm{D})$ của bồn bồn, cỏ bàng và năn tượng ở nghiệm thức không bón $\mathrm{CaCO}_{3}$ và có bón $\mathrm{CaCO}_{3}$

Ghi chú: a,b: giá trị trung bình có kí tư a,b khác nhau thì khác biệt có ý nghĩa thống kê giữa hai nghiệm thức bón phân trong cùng một loài cây dựa vào kiểm định T-test $(p<0,05)$.
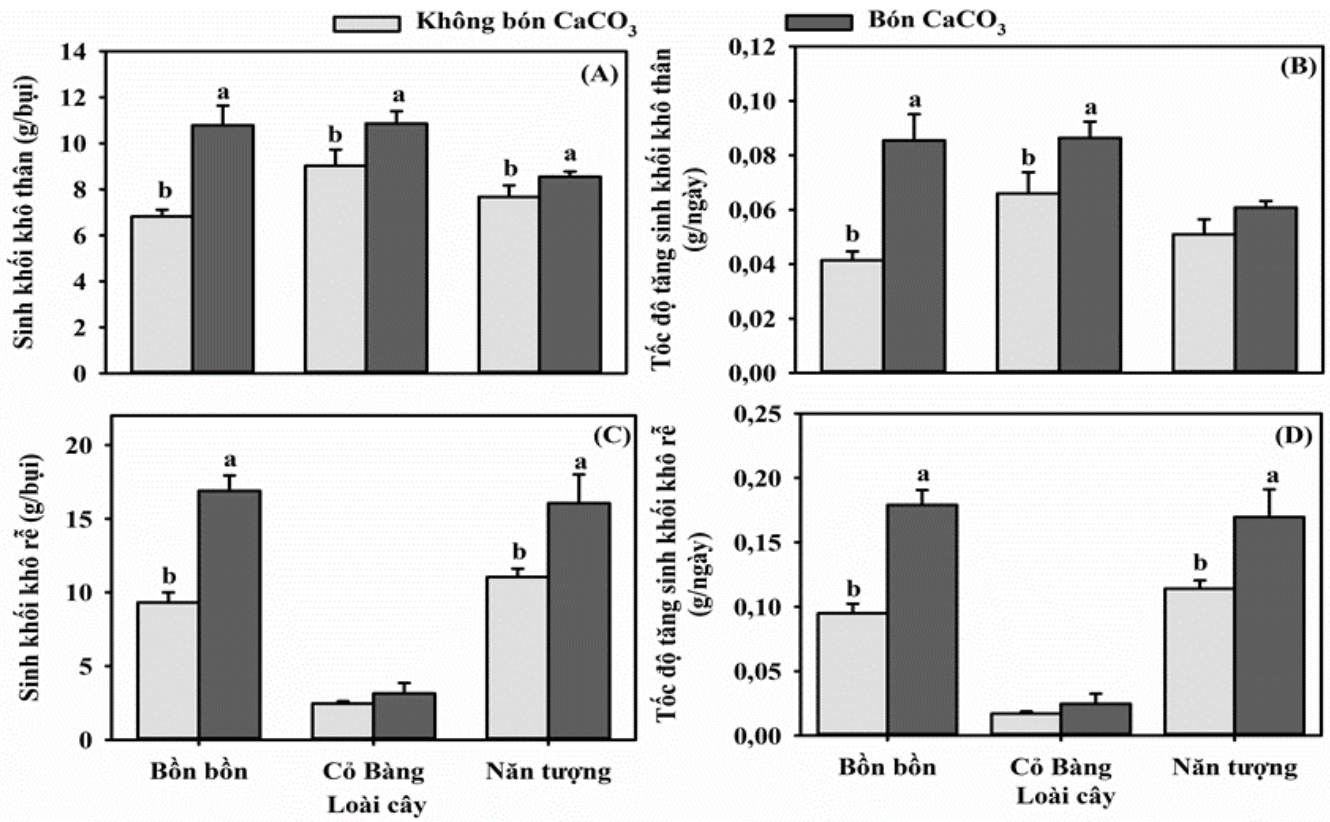

Hình 5. Sinh khối khô thân (A), tốc độ tăng sinh khối khô thân (B), sinh khối khô rễ (C) và tốc độ tăng sinh khối khô rễ (D) của bồn bồn, cỏ bàng và năn tượng ở nghiệm thức không bón $\mathrm{CaCO}_{3}$ và có bón $\mathrm{CaCO}_{3}$

Ghi chú: a,b: giá trị trung bình có ki tụ a,b khác nhau thì khác biệt có ý nghĩa thống kê giũa hai nghiệm thức bón phân trong cùng một loài cây dụa vào kiểm định T-test ( $p<0,05)$. 


\subsection{Sinh khối khô của thân và rễ}

Sự tích lũy sinh khối khô ở phần thân của bồn bồn, cỏ bàng và năn tượng ở nghiệm thức có bón $\mathrm{CaCO}_{3}$ cao hơn ở nghiệm thức không bón $\mathrm{CaCO}_{3}$ $(\mathrm{p}<0,05$; Hình $5 \mathrm{~A})$. Việc bón vôi cải thiện $\mathrm{pH}$ đất góp phần tăng $36,7 \%$ sinh khối khô phần thân của cây bồn bồn, $16,9 \%$ ở cỏ bàng và $10,3 \%$ ở năn tượng. Trong đó, hiệu quả của việc cải thiện $\mathrm{pH}$ đất bằng vôi giúp cải thiện tốc độ tăng sinh khối khô phần thân tốt nhất ở loài bồn bồn và cỏ bàng $(0,91$ g/ngày) ( $<<0,05$; Hình $5 \mathrm{~B})$. Theo Moreira and Fageria (2010), chất khô trong chồi của cỏ linh lăng càng tăng lên khi tỷ lệ vôi bón càng nhiều hơn. Điều này cho thấy việc bón vôi cải tạo đất đã giúp cây tích lũy sinh khối khô thân tốt hơn trong điều kiện đất phèn.

Có sự tương tác giữa hai nhân tố loài cây và phân bón đến sinh khối khô rễ cây và tốc độ tăng sinh khối khô của rễ ( $<<0,05$; Bảng 2$)$. Sinh khối khô rễ cây bồn bồn và năn tượng ở nghiệm thức có bón $\mathrm{CaCO}_{3}$ là cao nhất (16,1-16,9 $\mathrm{g} / \mathrm{bụi})$ và tương ứng tốc độ tăng sinh khối khô rễ là $0,17-0,18 \mathrm{~g} /$ ngày. Hiệu quả khi sử dụng $\mathrm{CaCO}_{3}$ góp phần gia tăng 44,9\% sinh khối khô phần rễ của cây Bồn bồn và $27,9 \%$ của cây
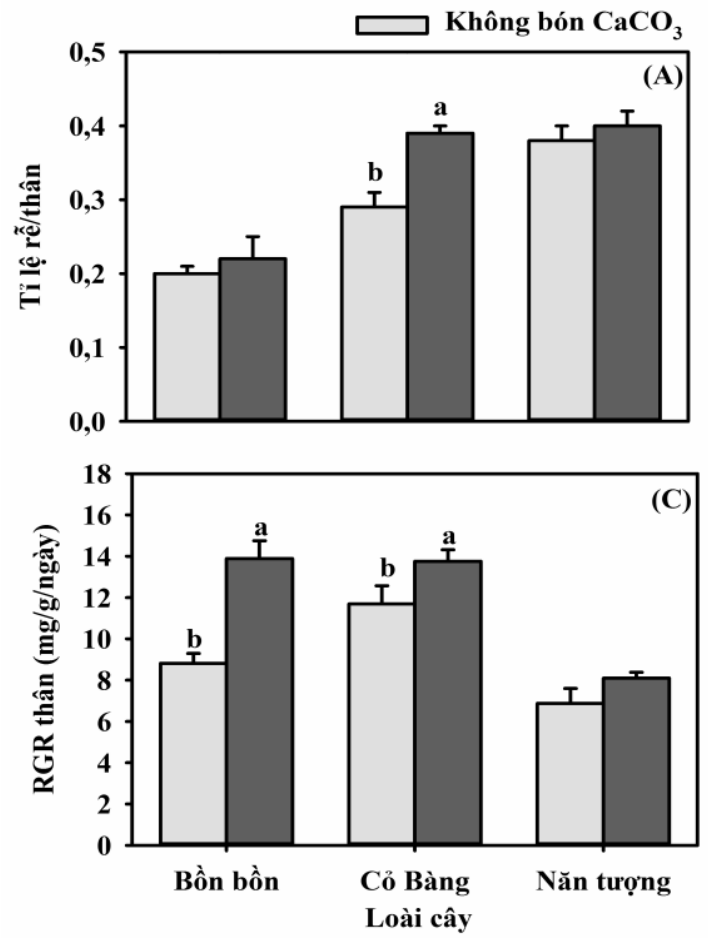

năn tượng. Tương tự, Chang and Sung (2004) nhận thấy rằng bón vôi làm tăng trọng lượng khô của rễ lúa. Theo Zhang et al. (2020), bón vôi cải thiện sự phát triển rễ của giống lúa B690 (Oryza sativa) trong đất phèn bằng cách giảm nồng độ $\mathrm{Al}$ trao đổi trong đất, đồng thời bón vôi tăng cường sự hấp thu đạm (N) trong đất của giống lúa B690.

\subsection{Tỉ lệ sinh khối rễ/thân, số lá và tốc độ tăng trưởng tương đối của cây}

Tỉ số sinh khối giữa rễ/thân là chỉ số sinh học đánh giá khả năng tăng trưởng của thân và rễ cây. Kết quả ghi nhận chỉ có cây cỏ bàng có sự khác biệt về tỉ lệ sinh khối rễ/thân, ở nghiệm thức có bón $\mathrm{CaCO}_{3}(0,33)$ cao hơn ở nghiệm thức đối chứng là $0,16(\mathrm{p}<0,05$; Hình $6 \mathrm{~A})$. Qua đó cho thấy khi sử dụng $\mathrm{CaCO}_{3}$ cải thiện $\mathrm{pH}$ đất phèn giúp sự phát triển hệ rễ cây cỏ bàng tốc độ tích lũy chất khô cao hơn so với phần thân cây. Sự phân bổ tỉ lệ rễ/thân cao trong môi trường nghèo dinh dưỡng, nơi cạnh tranh của bộ phận rễ dưới mặt đất chiếm ưu thế. Bên cạnh đó, sự gia tăng tỉ lệ rề/thân tăng nhanh có thể là do sự phát triển tương đối nhanh và lớn của rễ tìm kiếm các chất dinh dưỡng, điều này phù hợp với lý thuyết phân vùng sinh khối tối ưu (Bloom et al., 1985).
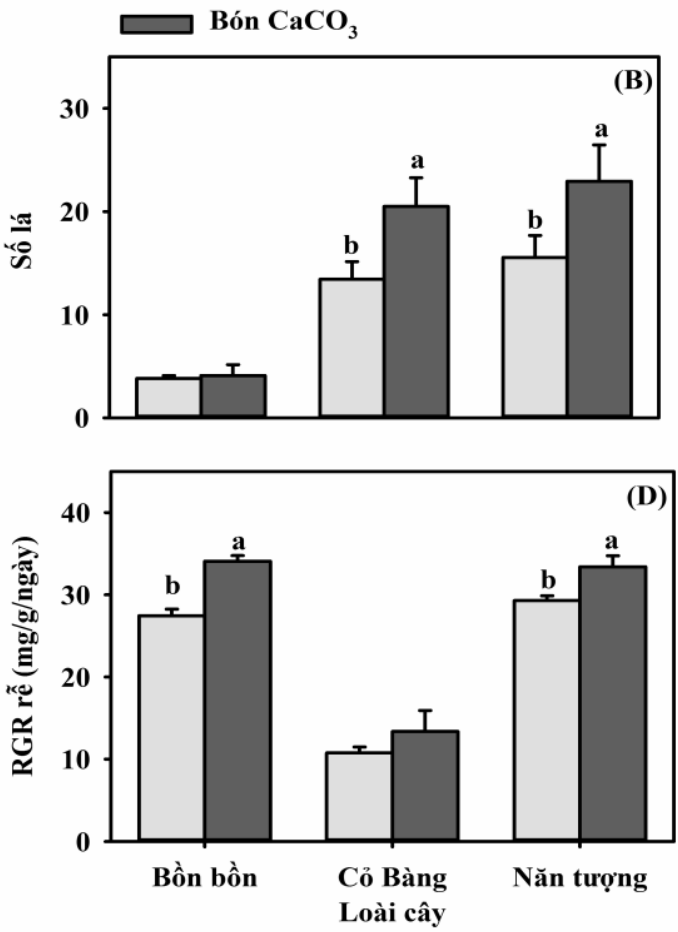

Hình 6. Tỉ lệ sinh khối rễ/thân (A), số lá (B), RGR thân (C) và RGR rễ (D) của bồn bồn, cỏ bàng và năn tượng ở nghiệm thức không bón $\mathrm{CaCO}_{3}$ và có bón $\mathrm{CaCO}_{3}$

Ghi chú: a,b: giá trị trung bình có kí tụ a,b khác nhau thi khác biệt có ý nghĩa thống kê giũa hai nghiệm thức bón phân trong cùng một loài cây dựa vào kiểm định T-test ( $p<0,05)$. 
Số lá của cỏ bàng và năn tượng ở nghiệm thức có bón $\mathrm{CaCO}_{3}$ cao hơn so với cây trồng ở nghiệm thức không bón $\mathrm{CaCO}_{3}(\mathrm{p}<0,05$; Hình $6 \mathrm{~B})$. Số lá cây cỏ bàng và năn tượng ở nghiệm thức bón $\mathrm{CaCO}_{3}$ tăng tương ứng 34,4 và $32,2 \%$ số lá so với cây trồng ở nghiệm thức đối chứng. Tương tự ghi nhận của Shaha et al. (2012), nghiên cứu trên rau muống (Ipomoea aquatica) cho thấy cây tăng $6,76 \%$ số lá ở nghiệm thức có bón vôi và tăng $33,33 \%$ số lá ở nghiệm thức sử dụng vôi kết hợp với phân chuồng.

Tốc độ tăng trưởng tương đối (RGR) sinh khối khô phần thân cây bồn bồn và cỏ bàng ở nghiệm thức bón $\mathrm{CaCO}_{3}$ là cao nhất $(\mathrm{p}<0,05$; Hình $6 \mathrm{C})$. Sự tăng năng suất chất khô của cây trồng trong điều kiện bón vôi là do khả năng cải thiện đất của $\mathrm{Ca}^{2+}$ và giảm độ chua của đất (Fageria and Baligar, 2003). Ngoài ra, bón vôi còn tăng cường sự khoáng hóa $\mathrm{N}$ hữu cơ cung cấp dinh dưỡng cho sự phát triển của cây (Edmeades and Ridley, 2003). Moreira and Fageria (2010) ghi nhận bón vôi là một trong những cách làm phổ biến và hiệu quả nhất để điều chỉnh độ chua của đất và cải thiện năng suất cỏ linh lăng. Cỏ bàng có sự phát triển chiều dài rễ cao nhất (Hình $3 \mathrm{C}$ ) trong 3 loài cỏ nghiên cứu, tuy nhiên, sinh khối khô rễ, tốc độ tăng sinh khối khô rễ và RGR rễ không có sự khác biệt (p>0,05; Hình 5C\&5D; Hình 6D).

\subsection{Chỉ số diệp lục tố}

Chỉ số diệp lục tố (SPAD) trong lá cũng là một trong những chỉ tiêu sinh hóa quan trọng nhất đối với thực vật trong các điều kiện môi trường khắc nghiệt. Trong nghiên cứu này, chỉ số SPAD bị ảnh hưởng bởi yếu tố bón $\mathrm{CaCO}_{3}$ để cải thiện đất $(\mathrm{p}<0,05$; Hình 7$)$. Trong đó, chỉ số diệp lục tố của bồn bồn và năn tượng ở nghiệm thức có $\mathrm{CaCO}_{3}$ cao hơn ở nghiệm thức không có $\mathrm{CaCO}_{3}$ (Hình 7), đồng thời chỉ số năng suất chất xanh của bồn bồn và năn tượng cao hơn trên cây trồng ở nghiệm thức có $\mathrm{CaCO}_{3}$ (Hình 4A). Parthasarathi et al. (2012) đã chứng minh SPAD tăng liên quan đến sự gia tăng năng suất ở cây trồng. Sự gia tăng đáng kể hàm lượng SPAD trong lá của bồn bồn và năn tượng có thể là do tình trạng dinh dưỡng của đất được cải thiện sau khi bón $\mathrm{CaCO}_{3}$ (Panhwar et al., 2014). Chỉ số SPAD ở nghiệm thức đối chứng thấp hơn, điều này có thể liên quan đến $\mathrm{pH}$ trong đất như nghiên cứu của Baquy et al. (2017), chỉ số diệp lục trong lá thấp hơn ở điều kiện $\mathrm{pH}$ đất thấp hơn và tăng cao hơn ở điều kiện $\mathrm{pH}$ đất cao hơn trên cây lúa mì và cải dầu.

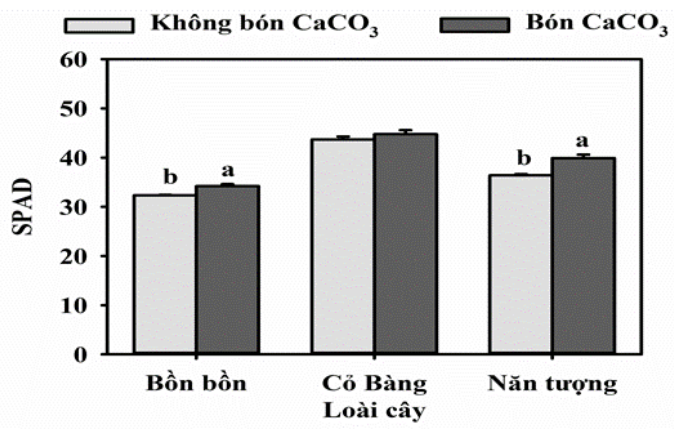

Hình 7: Chỉ số diệp lục tố trong lá của bồn bồn, cỏ bàng và năn tượng ở nghiệm thức không bón $\mathrm{CaCO}_{3}$ và có bón $\mathrm{CaCO}_{3}$

Ghi chú: a,b: giá trị trung bình có ki tụ a,b khác nhau thì khác biệt có ý nghĩa thống kê giữa hai nghiệm thức bón phân trong cùng một loài cây dựa vào kiểm định T-test $(p<0,05)$.

Tóm lại, tùy vào mỗi loài cây sẽ có cơ chế và khả năng thích ứng khác nhau trong điều kiện đất phèn. Trong 3 loài cây thủy sinh này, do cỏ bàng có khả năng sống trên đất phèn vừa phải đến phèn nặng và pH rất thấp trong khoảng 2,8-3,3 (Kawahigashi et $a l ., 2008)$, và sống ở vùng thấp trũng ngập nước thường xuyên vào mùa lũ, có thể trồng những nơi đất phèn không trồng lúa được. Chính vì vậy, khi bón bổ sung $\mathrm{CaCO}_{3}$ trên đất phèn điều kiện $\mathrm{pH}$ cải thiện từ $\mathrm{pH} 3,02$ lên 4,02, cây cỏ Bàng chưa thể hiện sự cải thiện sinh trưởng, cụ thể sinh khối tươi phần thân, sinh khối rễ và chỉ số SPAD so với cây trồng trên đất phèn không bón $\mathrm{CaCO}_{3}$. Ngược lại, cây bồn bồn và năn tượng thể hiện tốt sự tăng trưởng sinh trưởng và tích lũy sinh khối trong điều kiện đất phèn được cải thiện $\mathrm{pH}$ bằng $\mathrm{CaCO}_{3}$.

\section{KẾT LUẬN VÀ KIẾN NGHI}

Sử dụng 2 tấn $\mathrm{CaCO}_{3} /$ ha giúp cải thiện $\mathrm{pH}$ trong đất phèn từ 3,02 tăng lên 4,02 trong 42 ngày ngâm đất. Bồn bồn và năn tượng có sinh trưởng và tích lũy sinh khối tốt hơn trong điều kiện đất phèn được cải thiện $\mathrm{pH}$ bằng $\mathrm{CaCO}_{3}$. Cây bồn bồn là loài có tiềm năng tích lũy sinh khối khô phần thân cao nhất kế đến là cỏ bàng và năn tượng.

Nghiên cứu kết hợp bón phân hóa học, phân hữu cơ, phân chuồng kết hợp nhiều mức vôi khác nhau để có cơ sở đánh giá được tiềm năng sinh khối tối đa của bồn bồn, cỏ bàng và năn tượng trên đất phèn ngập nước bỏ hoang.

\section{LỜI CẢM ƠN}

Nghiên cứu này được tài trợ bởi Dự án "Nâng cấp Trường Đại học Cần Tho" VN14-P6 bằng 
nguồn vốn vay ODA từ Chính phủ Nhật Bản (đề tài nhánh E6-10).

\section{TÀI LIỆU THAM KHẢO}

Baquy, M., Li, J. Y., Xu, C. Y., Mehmood, K., \& Xu, R. K. (2017). Determination of critical pH and $\mathrm{Al}$ concentration of acidic Ultisols for wheat and canola crops. Solid Earth, 8(1), 149-159.

Beetle, A.A. (1941). Studies in the genus Scirpus L. III. The American species of the section Lacustres Clarke. American Journal of Botany, 28, 691-700.

Bloom, A. J., Chapin III, F. S., \& Mooney, H. A. (1985). Resource limitation in plants-an economic analogy. Annual review of Ecology and Systematics, 16(1), 363-392. https://doi.org/10.1146/annurev.es.16.110185.0 02051.

Caires, E.F., J.C. L. Corrêa, S. Churka, G. Barth, \& Garbuio, F.J. (2006). Surface application of lime ameliorates subsoil acidity and improves root growth and yield of wheat in an acid soil under no-till system. Sci. Agric., 63(5), 502-509.

Carver, B.F., and Ownby, J.D. (1995). Acid soil tolerance in wheat. Advances in Agronomy, 54, 117-173.

Chang, C.S. \& Sung, J.M. (2004). Nutrient uptake and yield responses of peanuts and rice to lime and fused magnesium phosphate in an acid soil. Field Crop Res., 89, 319-325.

Cho, K.M., Ranamukhaarachchi, S.L., \& Zoebisch, M.A. (2002). Cropping systems on acid sulfate soils in the central plain of Thailand: constraints and remedies. The $17^{\text {th }}$ WCSS, 812, 1-10.

Doss, B.D., Dumas, W.T., \& Lund, Z.F. (1979). Depth of lime incorporation for correction of subsoil acidity. Journal of Agronomy, 71, 541-544.

Edmeades, D.C. \& Ridley, A.M. (2003). Using lime to ameliorate topsoil and subsoil acidity. In: Rengel Z. (Ed.), Handbook of soil acidity (pp. 297- 336). Marcel Dekker Inc. New York, USA.

Fageria, N.K. ^ Baligar, V.C. (2003). Fertility management of tropical acid soil for sustainable crop production. In: Rengel Z. (Ed.), Handbook of soil acidity (pp. 359-385). Marcel Dekker Inc. New York, USA.

Fageria, N.K. \& Baligar, V.C. (2008). Ameliorating soil acidity of tropical oxisols by liming for sustainable crop production. Adv. Agron., 99, 345-399.

Fältmarsch, R.M., M. E. Åström, \& Vuori, K.M. (2008). Environmental risks of metals mobilised from acid sulphate soils in Finland: a literature review. Boreal Environment Research, 13, 444-456.

Fisher, R.A. (1921). Some remarks on the methods formulated in a recent article on "The quantitative analysis of plant growth". Annals of Applied Biology, 7, 367-372.

Huu, N.H. (2017). A study of the drivers of land use change in the Ha Tien plain region of the Mekong Delta, Vietnam. A thesis submitted for the degree of Doctor of Philosophy at The University of Queensland in 2017, School of Earth and Environmental Sciences. 220 pages.

Kawahigashi, M., N.M. Do, V.B. Nguyen \& Sumida, H. (2008). Effects of drying on the release of solutes from acid sulfate soils distributed in the Mekong Delta, Vietnam. Soil Science and Plant Nutrition, 54, 495-506. doi: 10.1111/j.17470765.2008.00275.x.

Kochian, L.V., Pineros, M.A., \& Hoekenga, O.A. (2005). The physiology, genetics and molecular biology of plant aluminum resistance and toxicity. Plant and Soil, 274(1-2), 175-195.

Lê Văn Dũng, Tất Anh Thư, Nguyễn Duy Linh \& Võ Thị Gương (2018). Cải thiện đặc tính bất lợi của đất phèn nhiễm mặn và năng suất lúa qua sử dụng phân hữu cơ và vôi trong điều kiện nhà lưới. Tạp chi Khoa hoc Truờng Đại học Cần Tho, 54, 65-74. DOI: 10.22144/ctu.jsi.2018.067.

Macia, J.M. \& Balslev, H. (2000). Use and management of Totora (Schoenoplectus californicus, Cyperaceae) in Ecuador. Economic Botany, 54(1), 82-89.

Moges, T., A. Melese, \& Tadesse, G. (2017). Effects of lime and phosphorus fertilizer levels on growth and yield components of malt barley (Hordeum distichum L.) in Angolelana Tera District, North Shewa Zone, Ethiopia. Advances in Plants \& Agriculture Research, 8(6), 582-589.

Moreira, A.N \& Fageria, K. (2010). Liming influence on soil chemical properties, nutritional status and yield of alfalfa grown in acid soil. $R$. Bras. Ci. Solo, 34, 1231-1239.

Opala, P.A. (2017). Influence of lime and phosphorus application rates on growth of maize in an acid soil. Advances in Agriculture Article ID 7083206, 5 pages. https://doi.org/10.1155/2017/7083206.

Panhwar, Q., Naher, U., Radziah, O., Shamshuddin, J., \& Razi, I.M. (2014). Bio-fertilizer, ground magnesium limestone and basalt applications may improve chemical properties of Malaysian acid sulfate soils and rice growth. Pedosphere, 24, 827-835.

Parthasarathi, T., Vanitha, K., Lakshamanakumar, P., \& Kalaiyarasi, D. (2012). Aerobic ricemitigating water stress for the future climate change. Int. J. Agron. Plant Prod., 3, 241-254.

Roy, A. K., Sharma, A., \& Talukder, G. (1988). Some aspects of aluminum toxicity in plants. The Botanical Review, 54(2), 145-178. 
Sardinha, M., Müller, T., Schmeisky, H., \& Joergensen, R. G. (2003). Microbial performance in soils along a salinity gradient under acidic conditions. Applied Soil Ecology, 23(3), 237-244.

Shaha, S.C., M.A., Kashem, \& Osman, K.T. (2012). Effect of lime and farmyard manure on the concentration of cadmium in water spinach (Ipomoea aquatica). International Scholarly Research Network, 1-6.

Shamshuddin, J., Sharifuddin, H. A. H., Che Fauziah, I., Edwards, D. G., \& Bell, L. C. (2010). Temporal changes in chemical properties of acid soil profiles treated with magnesium limestone and gypsum. Pertanika Journal of Tropical Agricultural Science, 33(2), 277-295.

Soil Survey Division Staff (1993). Soil Survey Manual. USDA Handbook 18, U.S. Government Printing Office, Washington, DC.

Sumner, M. E., Radcliffe, D. E., McCray, M., Carter, E., \& Clark, R. L. (1990). Gypsum as an ameliorant for subsoil hardpans. Soil Technology, 3(3), 253-258.

Trang, N.T.D., Liang, J.B., Liao, X.D., \& Ismail, M.Y. (2002). Growth and nutritive value of some tropical plants species grown in cattle wastewater. In: Proceeding of Malaysian Science and Technology Congress (MSTC) 2002, Symposium C: Life Sciences, $12^{\text {th }}-14^{\text {th }}$ December 2002, Kuching, Sarawak, Malaysia. BR 15, pp. 379-383.

Trang, N.T.D., Linh, V.C., Mo, L.T.N \& Brix, H. (2018). Phytoremediation potential of Typha orientalis and Scirpus littoralis in removal of nitrogen and phosphorus from intensive whiteleg shrimp wastewater. E3S Web of Conferences 68, 04003 (2018). eISSN: 2267-1242.

DOI: https://doi.org/10.1051/e3sconf/20186804003
Trịnh Thị Thu Trang \& Nguyễn Mỹ Hoa (2007). Ảnh hưởng việc bón chất thải biogas, urê, vôi đến lượng đạm khoáng trên đất phèn trung bình canh tác lúa và mối tương quan giữa hàm lượng đạm khoáng trong đất và sự hấp thu đạm của cây. Tạp chí Khoa học trương Đại hoc Cần Tho, 7, 58-66.

Uchida, R. \& Hue, N.V. (2000). Chapter 6: Soil Acidity and Liming. In: Plant Nutrient Management in Hawaii's Soils: Approaches for Tropical and Subtropical Agriculture (pp. 101111). College of Tropical Agriculture and Human Resources, University of Hawaii at Manoa. ISBN 1-929235-08-8.

Ueno, K.A. (2004). Mechanism of soil acidification in acid sulfate soils. Annual Report of Research Institute for Biological Function, 4, 25-33.

Valipour, A., \& Ahn, Y. H. (2016). Constructed wetlands as sustainable ecotechnologies in decentralization practices: a review.

Environmental Science and Pollution Research, 23, 180-197.

Xuan, V.T., \& Matsui, S. (1998). Development of farming systems in the Mekong Delta. Ho Chi Minh City Publishing House Vietnam, 318 pages.

Yuan, Z., Cao, Q., Zhang, K., Ata-Ul-Karim, S.T., Tian, Y., Zhu, Y., Cao, W., \& Liu, X. (2016). Optimal leaf positions for SPAD meter measurement in rice. Front. Plant Sci., 7, 1-10.

Zhang, H.Z., X.Q. Zhao, Y.L., Chen, J.L., Wang \& Shen, R.F. (2020). Improved root growth by liming aluminum-sensitive rice cultivar or cultivating an aluminum-tolerant one does not enhance fertilizer nitrogen recovery efficiency in an acid paddy soil. Plants, 9, 1-14. 